\title{
Vaccines against Coronavirus Disease: Target Proteins, Immune Responses, and Status of Ongoing Clinical Trials
}

\author{
Rike Syahniar ${ }^{1 *}$ (D), Maria Berlina Purba² ${ }^{(D)}$, Heri Setiyo Bekti ${ }^{3}$ and \\ Mardhia Mardhia ${ }^{4}$
}

${ }^{1}$ Department of Microbiology and Parasitology, Faculty of Medicine and Health, University of Muhammadiyah Jakarta, Jl. KH. Ahmad Dahlan, Ciputat, Cirendeu, Jakarta Selatan, Daerah Khusus Ibukota Jakarta 15419, Indonesia.

${ }^{2}$ National Quality Control Laboratory of Drug and Food, National Agency for Drug and Food Control, J. Percetakan Negara No.23, Jakarta Pusat, Indonesia.

${ }^{3}$ Department of Medical Laboratory Technology, Polytechnic of Health Denpasar, Jl. Sanitasi No.1, SidakaryaDenpasar Selatan, Bali, 80224, Indonesia.

${ }^{4}$ Department of Microbiology, Faculty of Medicine, Tanjungpura University,Jl. Prof. Dr. Hadari Nawawi, Pontianak, 78124, Indonesia.

\begin{abstract}
The coronavirus disease (COVID-19) pandemic, caused by severe acute respiratory syndrome coronavirus 2 (SARS-CoV-2), has infected more than 26 million individuals and caused 871,166 deaths globally. Various countries are racing against time to find a vaccine for controlling the rapid transmission of infection. The selection of antigen targets to trigger an immune response is crucial for vaccine development strategies. The receptor binding domain of the subunit of spike 1 protein is considered a promising vaccine candidate because of its ability to prevent attachment and infection of host cells by stimulating neutralizing antibodies. The vaccine is expected to mount a sufficient immunogenic response to eliminate the virus and store antigenic information in memory cells for long-term protection. Here, we review the ongoing clinical trials for COVID-19 vaccines and discuss the immune responses in patients administered an adequate dosage to prevent COVID-19.

Keywords: COVID-19, Immune Response, SARS-CoV-2, Vaccine
\end{abstract}

\footnotetext{
*Correspondence: rikesyahniar@gmail.com

(Received: June 13, 2020; accepted: October 08, 2020)

Citation: Syahniar R, Purba MB, Bekti HS, Mardhia M. Vaccines against Coronavirus Disease: Target Proteins, Immune Responses, and Status of Ongoing Clinical Trials. J Pure Appl Microbiol. 2020;14(4):2253-2263. doi: 10.22207/JPAM.14.4.03

(C) The Author(s) 2020. Open Access. This article is distributed under the terms of the Creative Commons Attribution 4.0 International License which permits unrestricted use, sharing, distribution, and reproduction in any medium, provided you give appropriate credit to the original author(s) and the source, provide a link to the Creative Commons license, and indicate if changes were made.
} 


\section{INTRODUCTION}

Within a span of twenty years, several outbreaks have been caused by members of the coronavirus family, such as severe acute respiratory syndrome coronavirus (SARS-CoV) in 2002-2003, Middle East respiratory syndrome coronavirus (MERS-CoV) in 2012, and SARSCoV-2, which has recently caused a full-blown pandemic. Because the recently reported virus is genetically similar to SARS-CoV, it has been named as SARS-CoV- $2^{1}$. Initially, the virus was called the 2019-novel-Coronavirus. SARS-CoV-2 was first identified from China's Hubei province in the city of Wuhan in December 2019. The disease was initially characterized as an unknown form of pneumonia ${ }^{2}$.

As of September 5, 2020, a total of $26,468,031$ individuals worldwide have been reported to have COVID-19. Of the total number of cases, 871,166 patients have died. The case fatality rate (CFR) has reached $3.2 \%$ world wide. Till September 5, 2020, the United States of America (USA) had the highest number of confirmed COVID-19 cases. A total of 6,095,007 individuals have been confirmed to have COVID-19, along with a total of 185,687 deaths. In Southeast Asia, 4,592,952 COVID-19 cases have been confirmed. Of these, 82,182 people have lost their lives. In Indonesia, the total number of COVID-19-positive cases was 187,537 till September 5, 2020. Of these, $7,832(4,2 \%)$ have been reported to have died ${ }^{3}$.

Currently, countries are transitioning to the "new normal" where vaccines against the disease are highly anticipated. Various countries have begun working on developing a viable vaccine candidate against COVID-19 and are currently in the phase III of clinical trials. Each vaccine is unique owing to the characteristics of the pathogen, the property of the disease, and the target population for administration. Antigen selection is a major consideration in the development of vaccines. The vaccine must induce an antigenic immune response for generating immunological memory in lymphocytes for mounting a rapid response against subsequent viral infections. This immune response must be directed towards a defining structure expressed by the pathogen ${ }^{4}$. In this literature review, we discuss various target antigens for COVID-19 vaccines, their immune responses, and the status of vaccine trials.

\section{Classification of Coronaviruses}

SARS-CoV-2, MERS-CoV, and SARSCoV belong to subfamily Orthocoronavirinae of family Coronaviridae and order Nidovirales². Coronaviruses comprise four genera, including alphaCoV, betaCoV, deltaCoV, and gammaCoV ${ }^{5}$. The betaCoV genus is divided into five lineages ${ }^{6}$. The alphaCoV (TGEV, PEDV, FIPV, CCOV) and betaCoV (MHV, BCoV) only infect mammals? DeltaCoVs, namely HKU15, HKU16, HKU17, HKU18, HKU19, HKU20, and HKU21, cause infection in birds and pigs8. Seven of the coronavirus groups have been found in humans. HCoV-HKU1, HCoVOC43, HCoV-229E, and HCoV-NL63 cause upper respiratory tract infections that are self-limiting in immunocompetent individuals. However, SARSCoV-2, MERS-CoV, and SARS-CoV can cause severe distress in respiratory as well as extra-respiratory regions with variable clinical manifestations ${ }^{6}$.

\section{Structure and Genome of SARS-COV-2}

SARS-CoV-2 has a crown-like spherical shape, with a virion of 70 to $90 \mathrm{~nm}$ size, which is similar to that of SARS-CoV' . The positive-sense RNA of the SARS-CoV-2 genome has a size of $\sim 30 \mathrm{~kb}$, consisting of 6-11 open reading frames (ORFs) ${ }^{9}$. Guanine and cytosine content was $38 \%{ }^{10}$. The ORF region covers $67 \%$ of the genome, which encodes 16 putative nonstructural proteins (NSPs), along with accessory and structural proteins. In SARS-CoV, NSP1 is a nuclease that is involved in splitting host mRNA, leading to host termination ${ }^{11}$. NSP1 may play a role in destroying host immunity. Other putative NSPs are papain-like (NSP3), chymotrypsin-like, 3c-like, or primary proteases (NSP5), primases (NSP7, NSP8), RNA-dependent RNA polymerases (NSP12), and helicases (NSP13). Other NSPs may have a role in transcription and replication of the viruses ${ }^{12}$. In addition to NSP, there are major structural proteins, including spike surface glycoproteins (S), membranes (M), nucleocapsid proteins (N), and envelopes (E), which are derived from host lipid bilayers embedded in the helical nucleocapsid base of viral RNA ${ }^{9,13}$. However, SARS-CoV-2 does not have a hemagglutinin esterase gene that is typically found in lineage-A BetaCoV ${ }^{12}$.

\section{Host-Pathogen Interactions}

The glycoprotein $S$ consists of two subunits, S1 and S2. S1 plays a role in receptor 
binding, whereas S2 is involved in fusion of the cell membrane ${ }^{21}$. Receptor binding domain (RBD) S1 links with ACE2 to activate the engulfment of the SARS-CoV-2 virions, thereby exposing them to endosomal proteases. In endosomes, the S1 subunit is cleaved, which then merges into the host membrane. The S1 domains of SARS-CoV and SARS-CoV-2 have 50 matching amino acids, although there are some variations in the amino acids within major residues. In particular, SARSCoV- 2 shares $88 \%$ similarity with two sequences of SARS-CoV obtained from bats ${ }^{22}$. S2 subunits containing fusion peptides, transmembrane domains, and cytoplasmic domains are all highly conserved. Similar to SARS-CoV, the ACE2 receptor is required for the internalization of SARS-CoV-2 and Serin protease TMPRSS2 to prime protein $\mathrm{S}^{23,24}$.

The identification of receptors is one of the most important targets for immune host supervision and human intervention strategies. Structural analysis and mutagenesis revealed that the RBD pattern of SARS-CoV-2 had higher affinity for ACE2 binding than the RBD of SARS-CoV ${ }^{23,24}$. On the other hand, studies using pull-down protein assay ${ }^{25}$ and cytometry assay ${ }^{26}$ show that the affinity of the spike protein towards ACE2 receptor is less potent than that of spike protein of SARS-CoV. Interestingly, the study of Cryo-EM revealed that the RBD of SARS-CoV spike protein is mostly in an upright state to facilitate host receptor binding ${ }^{27,28}$. However, the RBD on the SARS-CoV-2 spike protein is largely in a horizontal state, which creates difficulty in binding to the host receptor. Therefore, despite the higher affinity of SARSCoV-2 RBD towards the ACE2 receptor, it is less accessible than the SARS-CoV RBD ${ }^{24,29}$. This shows that the binding of SARS-CoV-2 Spike protein with the ACE2 receptor is not much different from the binding of SARS-CoV Spike protein.

SARS-CoV-2 relies on other strategies to sustain its infectivity while maintaining its less accessible RBD, namely the activation of the host proteases. The activation of host proteases plays a significant role in coronavirus infection and pathogenesis. Entry of SARS-CoV-2 can be activated via cell surface proteases such as furin, lysosomal proteases, and other proteases, which have a cumulative effect on viral entry ${ }^{25}$. Furin is a protein conversionase (PCS), a crucial group of host proteases. To manage the mechanism of cell entry, increase virulence, and spread, various viruses including coronaviruses use furin and other PCS from constitutive protein secretion pathways ${ }^{30,31}$. Immune Responses

When a viral infection occurs, macrophages, dendritic cells, and neutrophils slow the development of the virus and prevent it from causing symptoms through a nonspecific innate immune response. They also initiate an adaptive immune response that produces antibodies specific to the virus and the T-cells enhance cellular immunity by removing infected cells. Adequate innate and adaptive immune responses can control the development of re-infection ${ }^{32}$. To evaluate the vaccine-induced immune response, validation of immunodiagnostic assays using the appropriate antigen is required.

\section{Innate Immune Response}

Effective innate immune response by interferon (IFN) type 1 and its downstream cascade can control viral replication. Pathogen-

Tabel 1. Coronaviruses in Human

\begin{tabular}{llll}
\hline Virus & Group & Receptor & Ref. \\
\hline HCoV-OC43 (A- lineage) & betaCoVs & HLA Class I Antigen & 14 \\
HCoV-HKU1 (A- lineage) & betaCoVs & 9-O-acetylated sialic acid & 15 \\
HCoV-229E & alphaCoVs & hAPN & 16 \\
HCoV-NL63 & alphaCoVs & ACE 2 & 17 \\
SARS-CoV (B and C lineage) & betaCoVs & ACE 2 & 18 \\
SARS-CoV-2 (B and C lineage) & betaCoVs & ACE 2 & 19 \\
MERS-CoV (B and C lineage) & betaCoVs & DPP4 & 20
\end{tabular}

Abbreviations: Human Leukocyte Antigen (HLA); Angiotensin converting enzyme 2 (ACE 2); human aminopeptidase N (hAPN); Dipeptidyl peptidase-4 (DPP4) 
associated molecular patterns (PAMPs) in the form of genomic RNA viruses, such as coronaviruses, are identified by endosomal RNA receptors (TLR3 and TLR7) and cytosolic RNA sensors (RIG-I / MDA5) ${ }^{33}$. The activation of this interaction directs the transcription factor NF-kB and the interferon regulatory factor (IRF), which is then translocated into the nucleus ${ }^{34}$.

This transcription factor induces the expression of IFN types I and III involved in cellular antiviral defenses and other proinflammatory cytokines, which provide defense against firstline viral infections at the entry point ${ }^{33,35}$. The resulting effect of IFN type I and III expression enhances intracellular antiviral defenses in adjacent epithelial cells, which aim to control the development of the virus. In addition, the release of IL- 6 and IL- $1 \beta$ promotes the recruitment of neutrophils and cytotoxic T cells. These activated neutrophils release leukotrienes and reactive oxygen species that induce pneumocytic and endothelial injuries, leading to acute lung diseases ${ }^{36}$. The development of COVID-19 caused a decrease in IFN during the course of initial infection. In vitro and in vivo studies conducted by Blanco et al. showed that the immune response cannot produce sufficient IFN I and III to check viral replication, while robust expression of cytokines is needed to activate effector cells ${ }^{11}$.

\section{Adaptive Immune Response}

Adaptive immune responses, intended to eliminate infected cells and viral particles, involve T lymphocytes (T cells) and B lymphocytes (which produce antibodies) ${ }^{37}$. Antigen-presenting cells create a cytokine microenvironment that determines the $\mathrm{T}$ cell response. To eliminate viruses from host cells, helper $T$ cells regulate the adaptive immune response by enabling cytotoxic $T$ cells and B cells; particularly, CD8 cytotoxic T-cells respond by releasing perforins, granzymes, and interferons (IFNs) ${ }^{38,39}$. A retrospective study of 452 COVID-19 patients showed significantly reduced levels of T-cells (CD 4 and CD 8) ${ }^{40}$. In severe clinical manifestations, the helper $T$ cell levels are quite low $^{40,41}$. In addition, the levels of regulatory T cells are significantly lower and evidently damaged in severe cases. This shows that there is a disruption in the function and regulation of host $T$ cells, leading to disease manifestations. Comparison between patients with severe and mild forms of the disease indicated elevated expression of IFNs from T-Cells (CD8+ and CD4+) ${ }^{40}$. A study using flow cytometry comparing CD4 and CD8 markers found that the level of CD8 expression was higher than that of $C D 4^{42}$. However, this study did not explain the severity of the disease.

The humoral immune response, especially antibody production, inhibits the adhesion of SARS-CoV-2 to target cells and helps in neutralizing the virus ${ }^{37}$. A study involving 173 patients revealed that the presence of antibodies was less than $40 \%$ in the first week of onset, which increased to $100 \%$ (Ab), 94.3\% (IgM), and $79.8 \%$ (IgG) from the $15^{\text {th }}$ day onwards. The median seroconversion time for total antibodies (Ab), IgM, and IgG was day 11, day 12 , and day 14 , respectively ${ }^{43}$. Another study in critical and non-critical patients reported that the median time of seroconversion to IgG was 7 days after onset of symptoms ${ }^{44}$. Another study reported that $100 \%$ of the 285 patients tested positive for IgG in an acute antibody response to SARS-CoV-2 within 19 days after symptom onset. IgG and IgM titers remained stable for 6 days after seroconversion $^{45}$. Antibody levels are known to increase rapidly from the sixth day post-onset, accompanied by a decrease in viral load ${ }^{46}$.

The difference in seroconversion is influenced by various factors, one of which is the antigen used. Seroconversion to IgG occurred two days earlier, on average, for nucleoprotein $(\mathrm{N})$ than for protein $\mathrm{S}^{44}$. Seropositivity for anti-RBD IgG and anti-RBD IgM was higher than that for anti-N IgG and anti-N IgM after 14 days of symptom onset. Anti-SARS-CoV-2-RBD and anti-SARS-CoV2-N or IgG levels were correlated with the virus neutralization titer, which is important for the design of vaccine studies ${ }^{47}$.

Nucleocapsids and $S$ proteins trigger antibody responses between days 8 and 14 after the initial symptoms. Antibody against nucleocapsid protein shows better sensitivity than S protein of the virus in patients with more than 14 days of symptom onset ${ }^{48}$. Antibodies that appear during the first infection may not be able to neutralize the second infection entirely. On the contrary, due to the activation of the virus, antibodies form a complex with the second virus. In addition, some non-neutralizing antibodies that target the $S$ protein in the non-RBD section can lead to an increase in antibodies, which causes a 
dangerous immune response ${ }^{49}$. Using PAMPs of $\mathrm{S}$ protein from the virus as an antigen, the sensitivity and specificity of the tests were $88.66 \%$ and $90.63 \%$ in the combined IgM-IgG antibody testing kits, respectively ${ }^{50}$.

Immunological Profile of Recovered COVID-19 Patients

Studies have reported that the majority of individuals recovering from COVID-19 have detectable neutralizing antibodies, which are related to the number of virus-specific T cells ${ }^{51,52}$. Recovering COVID-19 patients permanently produce a strong $C D 4+T$ cell response against spike proteins of SARS-CoV-2, which was proportional to the magnitude of the anti-SARS-CoV-2 IgG and IgA titers. The TH1 response is prominent in COVID-19 cases, with little to no $\mathrm{TH} 2$ cytokines $^{53}$.

There relationship between antibody response and clinical improvement is unclear. Several studies have found high antibody levels in severe forms of the disease $\mathrm{A}^{43,54,55}$. A study using a modified cytopathogenic neutralization test based on the direct SARS-CoV-2 test and ELISA showed that patients with poor clinical classification have higher neutralizing antibody titers $(p=0.0227)^{54}$. Independent multivariate analysis showed that a higher $A b$ titer was strongly associated with clinical severity $(p=0.006)^{43}$. However, a cohort study revealed high titers of specific antibodies against RBD S1 and S2 proteins of SARS-CoV-2 in 175 patients with mild symptoms of COVID-19 ${ }^{56}$.

Studies using a chemiluminescent immunoassay reported that specific antibodies against SARS-CoV-2 disappear within 3 months of recovery ${ }^{57}$. Another study involving 1797 patients showed $91.1 \%$ seropositive cases both immediately after recovery and about 3 months after recovery ${ }^{58}$. However, in patients with SARSCoV and MERS-CoV antibodies, antibodies can last up to 2-3 years in recovered patients ${ }^{59,60}$. In a separate study, the NAb titer of patients $(28 / 30)$ decreased gradually over 3 months after symptom onset ${ }^{61}$. Among the recovered patients, the elderly and severely affected COVID-19 patients showed higher antibody levels ${ }^{58}$. In the majority of patients who have recovered from COVID-19, levels of IgG and neutralizing antibodies decrease within 2-3 months post infection ${ }^{52}$.

SARS-CoV-2-specific NAb titers were detected at 4 to 6 days, and the peak time for
NAbs was 10 to 59 days after disease onset ${ }^{61,62}$. NAb titers increased over time with increasing levels of IgG antibodies, which correlated well at the third week $(r=0.41)^{61}$. NAbs were unable to cross-react with SARS-CoV, and NAb titers were correlated with spike-binding antibody targeting. Studies among 175 patients who recovered from mild COVID-19 showed that the SARS-CoV-2 Nab titer appears to vary ${ }^{62}$.

To date, there is no evidence that people who have recovered from COVID-19 are protected against a second infection ${ }^{32}$. Infection of the six coronaviruses in humans can produce antibodies that cross-react with SARS-CoV-2 antibodies. Four coronaviruses infections are endemic in humans, causing common cold. Studies have reported that SARS-CoV-2-reactive CD4 + T cells are produced in $40 \%-60 \%$ of non-exposed individuals. This suggests cross-reactive T-cell recognition between the circulating common cold flu virus and the SARS-CoV- $2^{53}$. Studies using monoclonal antibodies targeting SARS-CoV have shown that they are not bound to the new coronavirus. As such, antibodies containing SARS-CoV from 2003 are not necessarily effective in preventing or treating COVID-1924. However, serological testing has limitations, and it is necessary to accurately distinguish between past infections due to preexisting antibodies against SARS-CoV, MERS-CoV, and the common cold coronavirus ${ }^{32}$. Therefore, it is important to verify the specificity of the serological test to avoid false-positive results ${ }^{55}$.

Immunopathology

When SARS-CoV-2 infects cells, active multiplication and shedding of the virus leads to lysis of the infected cells and damages molecular patterns, including ATP, nucleic acids, and ASC oligomers. Localized inflammation results in increased secretion of pro-inflammatory cytokines and chemokines, including macrophage inflammatory protein $1 \alpha$ (MIP1 $\alpha)$, IL-6, IP-10, MIP1 $\beta$, and MCP1. Furthermore, cytokines mobilize monocytes, macrophages, and T cells to the site of infection, increase farther reserves (by increasing IFN obtained by T cells) and create pro-inflammatory feedback loops. This leads to excess production of cytokines, resulting in cytokine storms. Cytokine storms can circulate to various organs, leading to multiple-organ damage $^{19}$. A study involving 123 COVID-19 
patients showed that IL-6 and IL-10 levels were higher in patients with severe disease than in patients with mild disease ${ }^{63}$. Moreover, nonneutralization antibodies generated by $B$ cells may facilitate SARS-CoV-2 infections via increased antibody-dependent enhancement (ADE), thereby aggravating organ damage ${ }^{19}$. The activation of immune cells from the circulation and the transmigration of lymphocytes into the airways can modify lymphopenia mechanisms and increase the neutrophil-lymphocyte ratio to approximately $80 \%$ in SARS-CoV-2-infected patients ${ }^{64}$.

\section{Vaccines}

DNA Vaccines

This vaccine consists of DNA molecules that encode the desired antigen and additional support for cell entry, thereby targeting specific cells, or costimulatory molecules. The concept of this vaccine is that DNA components are expressed in small amounts of antigenic proteins that promote antibodies, cytolytic T cells, and protective immune responses, which are generated quickly upon exposure to the actual antigen $^{65,66}$. Antigen-encoding sequences are obtained directly from DNA viruses or through reverse transcription of RNA viruses, which are then inserted into a plasmid between a strong promoter and a polyadenyl signal. Plasmids are replicated in bacterial cells and then purified for use as a vaccine ${ }^{67}$.

The safety profile of DNA vaccines must demonstrate the absence of integration of DNA vaccines into the human genome or induction of autoimmune reactions. Initially, DNA immunization showed limited immunogenicity in humans; however, in many vaccine trials, it induced protection in mice and non-human primates. Synthetic DNA is a feature that is resistant to temperature and cold chains, which is an important feature for delivery to locations with limited resources. Through improvements in the promoter design, manufacturing process, and administration, immunization of DNA vaccines in humans promises to be a platform to induce antibody neutralization and significant $T$ cell responses ${ }^{68}$. The synthetic DNA vaccine candidate, INO-4800, targets the S protein from SARS-CoV-2, which induces strong expression of $S$ protein in vitro and produces $T$ cell responses and antibodies after immunization in mice and guinea pigs. This vaccine, produced by Inovio Pharmaceuticals, has entered phase I of clinical trials (NCT04336410). mRNA Vaccines

The mRNA-based antiviral vaccine is highly immunogenic. In addition, the vaccine can minimize the risk of infection and mutagenesis by insertion due to natural degradation of mRNA in the cellular microenvironment. mRNA vaccines tend to be safer because they do not interact with the genome and are directly needed for the expression of encoded proteins. To increase efficiency, an adjuvant vaccine can be added to support the adaptive immune response in addition to the proper antigen ${ }^{69}$.

BNT162a1, BNT162b1, BNT162b2, and $B N T 162 c 2$ are four variants of messenger RNA (mRNA) vaccines made by Biontech SE/ Pfizer, which have entered phase I/II of clinical trials (NCT04380701) (NCT04368728). These four vaccine candidate variants expressed the RBD from the SARS-CoV-2 spike protein. Other vaccine candidates include mRNA-1273, produced by ModernaTX, Inc. mRNA-1273 expresses S protein from SARS-CoV-2 encapsulated in lipid nanoparticles (NCT04283461). Phase I of clinical trials have found the vaccine candidates to be safe; unwanted side effects show no pattern of concern and the vaccines are capable of inducing antibodies with high levels of viral neutralizing activity $^{70}$. Currently, the vaccine has completed phase 2 and has entered phase 3 of clinical trials (NCT04405076) (NCT04470427).

\section{Vector-Recombinant Protein Vaccines}

The recombinant DNA method allows cloning of viral genes into viruses, bacteria, fungi, insect cells, or plant cells that are not pathogenic to produce immunogenic proteins. Because only a portion of the viral genome is needed, there is no original virus to the vaccine produced; therefore, it is safer than the inactive vaccine. Viral proteins can be produced in large quantities through engineered organisms under purification conditions. Genes are inserted to replace genes that are not needed for virus replication in carriers when used as a vaccine or added to the viral genome $^{71}$.

Vector vaccines are based on vectors that have proven to be safe, allowing the production and release of immunogenic antigens from infected cells for a limited period of time. Poxviruses, 
adenoviruses, measles viruses, and togaviruses are the most commonly used vectors for developing vaccines for coronaviruses ${ }^{72}$. Current vaccine candidates made by Oxford University using an adenovirus vector called ChAdOx1 nCoV-19 have entered phase 3 of clinical trials (NCT04400838). ChAdOx1 nCoV-19 is made from a weak version of the adenovirus (ChAdOx1). The virus causes infection in chimpanzees but has been genetically altered so that it cannot multiply in the human body. The addition of genetic material has been carried out on ChAdOx1, which enables the production of SARS-CoV-2 Spike glycoprotein ${ }^{73}$.

There were no serious side effects associated with ChAdOx1 nCoV-19. ChAdOx1 nCoV-19 exhibits an acceptable safety profile, and homologous enhancement enhances antibody response. Neutralizing antibody responses were strongly correlated with antibody levels, as measured by ELISA. These results, together with the induction of humoral and cellular immune responses, support a large-scale evaluation of this vaccine candidate in an ongoing phase 3 of clinical trial $^{74}$.

Another vaccine candidate, Ad5-nCoV, has entered phase 2 of clinical trials (NCT04341389). An open label, non-randomized, phase 1 clinical study from Ad5-nCoV reported no serious side effects within 28 days after vaccination. On the $14^{\text {th }}$ day, peaking at 28 days after vaccination, neutralizing antibodies and antibodies were known to increase significantly, as assessed by ELISA and neutralization tests. In addition, on the $14^{\text {th }}$ day after vaccination, the T-cell response was found to peak ${ }^{75}$.

\section{Live attenuated vaccines}

Attenuated live vaccines provide nonspecific protection against lethal infections not associated with the vaccine target pathogen. The proposed trained innate response is one that may increase immunity and reduce levels of the virus and/or sequelae associated with COVID-19, similar to that reported for other viral infections. If this innate response is truly induced in ongoing clinical trials, recipients should benefit during the acute crisis period of the COVID-19 pandemic until a conventional vaccine is available. Death in COVID-19 cases is closely related to progressive pulmonary inflammation and ultimately sepsis.
BCG and MMR vaccination in immunocompetent individuals has no contraindications and may be highly effective in providing preventive measures for high-risk populations during the COVID-19 pandemic $^{76}$. Until August 29, 2020, BCG and MMR vaccines were currently underway in phase 3 of clinical trials in healthcare workers (NCT04357028) (NCT04327206).

\section{Inactivated vaccines}

Inactivated vaccines are produced by viruses/bacteria that are grown on culture media and then inactivated using heat or formaldehyde. The key to this procedure lies in finding the combination of the concentration of chemicals used and the reaction time needed to completely deactivate the virus ${ }^{77}$. Currently, the SARS-CoV-2 inactivated vaccine produced by Sinovac has entered phase 3 of clinical trial (NCT04456595).

\section{Dendritic Cell Vaccines}

Various studies have shown that patients infected with coronavirus show reduced $T$ cell response and modest neutralizing antibody titers $^{39-41}$. On the other hand, the T-cell response induced by the SARS-CoV-2 vaccine must be well controlled to avoid immunopathology. To produce long-term protection through cellular immune responses, dendritic cells and antigenpresenting cells can bring viral antigens to the immune system to enhance strong immunological resistance. Artificial antigen-presenting cell (AAPC) vaccines are designed to express viral proteins and immunize modulator genes to activate AAPCs and $T$ cells. This vaccine candidate has entered phase 1 of clinical trial (NCT04299724).

\section{Therapeutic vaccines}

Although the term "vaccine" is based more on prevention, in vaccine therapy, early post-infection interventions provide the greatest opportunity to halt the progression of any clinical disease. The therapeutic vaccine approach is based on the interaction of Fc fragments from antibodies with receptors present in cells of the immune system. This interaction can trigger an immunoregulatory response pathway ${ }^{78}$. A therapeutic vaccine produced by Immunitor LLC has been prepared using heat-activated plasma from a donor with COVID-19. At present, the vaccine has reached phase $\mathrm{I} / \mathrm{II}$ of clinical trial (NCT04380532). 


\section{CONCLUSION}

The innate immune response is triggered in the initial phases of infection, due to interferon type 1 , which is intended to inhibit further replication of the virus, and induction of an adaptive immune response. The adaptive immune response targets the continued infection of the virus, involving antibodies that inhibit further viral infections and increase production of proinflammatory cytokines. This results in elimination of infected cells; however, excessive production of pro-inflammatory cytokine storms causes multiorgan damage, in order to eliminate viral particles. Development of vaccine candidates based on viral genetics aims to increase the production of proinflammatory cytokines, elimination of infected cells, and induction of antibodies that can inhibit viral infections. Optimal vaccine discovery is expected to be one of the promising approaches towards tackling the COVID-19 pandemic.

\section{ACKNOWLEDGMENTS}

All the authors acknowledge and thank their respective Institutes and Universities.

\section{CONFLICTS OF INTEREST}

The authors declare that there is no conflict of interest.

\section{AUTHORS' CONTRIBUTION}

All authors listed have made a substantial, direct and intellectual contribution to the work, and approved it for publication

\section{FUNDING}

None.

\section{DATA AVAILABILITY}

Not applicable.

\section{ETHICS STATEMENT}

This article does not contain any studies with human participants or animals performed by any of the authors.

\section{REFERENCES}

1. WHO. Naming the coronavirus disease (COVID-19) and the virus that causes it. Published 2019. Accessed June 18, 2020. https://www.who.int/emergencies/ diseases/novel-coronavirus-2019/technical-guidance/ naming-the-coronavirus-disease-(covid-2019)-and- the-virus-that-causes-it

2. Cascella M, Rajnik M, Cuomo A, et al. Features, Evaluation, and Treatment of Coronavirus. In: StatPearls [Internet]. Treasure Island (FL): StatPearls Publishing; 2020 Jan-. Available from: https://www. ncbi.nlm.nih.gov/books/NBK554776/

3. WHO. WHO Coronavirus Disease (COVID-19) Dashboard | WHO Coronavirus Disease (COVID-19) Dashboard. Published 2020. Accessed September 6, 2020. https://covid19.who.int/

4. Hoft DF, Brusic V, Sakala IG. Optimizing vaccine development. Cell Microbiol. 2011;13(7):934-942 doi:10.1111/j.1462-5822.2011.01609.x

5. Chan JF-W, To KK-W, Tse H, Jin D-Y, Yuen K-Y. Interspecies transmission and emergence of novel viruses: lessons from bats and birds. Trends Microbiol. 2013;21(10):544-555. doi:10.1016/j.tim.2013.05.005

6. Li $\mathrm{H}, \mathrm{Liu} S M, Y u X H$, Tang $\mathrm{SL}$, Tang $\mathrm{CK}$. Coronavirus disease 2019 (COVID-19): current status and future perspectives. Int $J$ Antimicrob Agents. 2020;55(5):105951. doi:10.1016/j. ijantimicag.2020.105951

7. Maier HJ, Bickerton E, Britton P. Coronaviruses: Methods and protocols. Coronaviruses Methods Protoc. 2015;1282(1):1-282. doi:10.1007/978-1-49392438-7

8. Woo PCY, Lau SK, Lam CSF, et al. Discovery of Seven Novel Mammalian and Avian Coronaviruses in the Genus Deltacoronavirus Supports Bat Coronaviruses as the Gene Source of Alphacoronavirus and Betacoronavirus and Avian Coronaviruses as the Gene Source of Gammacoronavirus and Deltacoronavi. J Virol. 2012;86(7):3995-4008. doi:10.1128/jvi.0654011

9. Kumar S, Nyodu R, Maurya VK, Saxena SK. Morphology, Genome Organization, Replication, and Pathogenesis of Severe Acute Respiratory Syndrome Coronavirus 2 (SARS-CoV-2). Coronavirus Disease. 2019;2:23-31. doi: 10.1007/978-981-15-4814-7_3

10. Guo YR, Cao QD, Hong ZS, et al. The origin, transmission and clinical therapies on coronavirus disease 2019 (COVID-19) outbreak- An update on the status. Mil Med Res. 2020;7(1):11. doi: 10.1186/s40779-02000240-0

11. Blanco-Melo D, Nilsson-Payant BE, Liu WC, et al. Imbalanced Host Response to SARS-CoV-2 Drives Development of COVID-19. Cell. 2020;181(5):10361045.e9. . doi: 10.1016/j.cell.2020.04.026

12. Chan JF, Kok KH, Zhu Z, et al. Genomic characterization of the 2019 novel human-pathogenic coronavirus isolated from a patient with atypical pneumonia after visiting Wuhan [published correction appears in Emerg Microbes Infect. 2020 Dec;9(1):540]. Emerg Microbes Infect. 2020;9(1):221-236. Published 2020 Jan 28. doi: 10.1080/22221751.2020.1719902

13. Tu YF, Chien CS, Yarmishyn AA, et al. A Review of SARSCoV-2 and the Ongoing Clinical Trials. Int J Mol Sci. 2020;21(7):2657. Published 2020 Apr 10. doi:10.3390/ ijms21072657

14. Collins AR. HLA class I antigen serves as a receptor for human coronavirus OC43. Immunol Invest. 1993;22(2):95-103. doi:10.3109/08820139309063393 
15. Huang X, Dong W, Milewska A, et al. Human Coronavirus HKU1 Spike Protein Uses O -Acetylated Sialic Acid as an Attachment Receptor Determinant and Employs Hemagglutinin-Esterase Protein as a ReceptorDestroying Enzyme. J Virol. 2015;89(14):7202-7213. doi: 10.1128/jvi.00854-15

16. Yeager $\mathrm{CL}$, Ashmun RA, Williams RK, et al. Human aminopeptidase $\mathrm{N}$ is a receptor for human coronavirus 229E. Nature. 1992;357(6377):420-422. doi: $10.1038 / 357420 \mathrm{a0}$

17. Hofmann H, Pyrc K, van der Hoek L, Geier M, Berkhout B, Pohlmann S. Human coronavirus NL63 employs the severe acute respiratory syndrome coronavirus receptor for cellular entry. Proc Natl Acad Sci USA. 2005;102(22):7988-7993. doi:10.1073/ pnas.0409465102

18. Li W, Moore MJ, Vasilieva N, et al. Angiotensinconverting enzyme 2 is a functional receptor for the SARS coronavirus. Nature. 2003;426(6965):450-454. doi:10.1038/nature02145

19. Hoffmann M, Kleine-Weber $\mathrm{H}$, Schroeder $\mathrm{S}$, et al. SARS-CoV-2 Cell Entry Depends on ACE2 and TMPRSS2 and Is Blocked by a Clinically Proven Protease Inhibitor. Cell. 2020;181(2):271-280.e8. doi:10.1016/j. cell.2020.02.052

20. Wang N, Shi X, Jiang L, et al. Structure of MERS-CoV spike receptor-binding domain complexed with human receptor DPP4. Cell Res. 2013;23(8):986-993. doi: 10.1038/cr.2013.92

21. Song W, Gui M, Wang X, Xiang Y. Cryo-EM structure of the SARS coronavirus spike glycoprotein in complex with its host cell receptor ACE2. PLOS Pathog. 2018;14(8):e1007236. doi: 10.1371/journal. ppat.1007236

22. Lu R, Zhao X, Li J, et al. Genomic characterisation and epidemiology of 2019 novel coronavirus: implications for virus origins and receptor binding. Lancet. 2020;395(10224):565-574. doi: 10.1016/S01406736(20)30251-8

23. Chen Y, Guo Y, Pan Y, Zhao ZJ. Structure analysis of the receptor binding of 2019-nCoV. Biochem Biophys Res Commun. 2020;525(1):135-140. doi:10.1016/j. bbrc.2020.02.071

24. Wrapp D, Wang N, Corbett KS, et al. Cryo-EM structure of the 2019-nCoV spike in the prefusion conformation. Science. 2020;367(6483):1260-1263. doi:10.1126/ science.abb2507

25. Shang J, Wan Y, Luo C, et al. Cell entry mechanisms of SARS-CoV-2. Proc Natl Acad Sci U S A. 2020; 117(21): 11727-11734.

26. Ou X, Liu Y, Lei $X$, et al. Characterization of spike glycoprotein of SARS-CoV-2 on virus entry and its immune cross-reactivity with SARS-CoV. Nat Commun. 2020;11(1):1620. doi: 10.1038/s41467-020-15562-9

27. Gui M, Song W, Zhou H, et al. Cryo-electron microscopy structures of the SARS-CoV spike glycoprotein reveal a prerequisite conformational state for receptor binding. Cell Res. 2017;27(1):119-129. doi: 10.1038/cr.2016.152

28. Yuan Y, Cao D, Zhang Y, et al. Cryo-EM structures of MERS-CoV and SARS-CoV spike glycoproteins reveal the dynamic receptor binding domains. Nat Commun. 2017;8 :15092. doi: 10.1038/ncomms15092
29. Walls AC, Park YJ, Tortorici MA, Wall A, McGuire AT, Veesler D. Structure, Function, and Antigenicity of the SARS-CoV-2 Spike Glycoprotein. Cell. 2020;181(2):281292.e6. doi: 10.1016/j.cell.2020.02.058

30. Braun E, Sauter D. Furin-mediated protein processing in infectious diseases and cancer. Clin Transl Immunol. 2019;8(e1073). doi: 10.1002/cti2.1073

31. Izaguirre G. The Proteolytic Regulation of Virus Cell Entry by Furin and Other Proprotein Convertases. Viruses. 2019;11:837. doi: 10.3390/v11090837

32. WHO. "Immunity passports" in the context of COVID-19. Published 2020. Accessed June 1, 2020. https://www.who.int/news-room/commentaries/ detail/immunity-passports-in-the-contextof-covid-19?gclid=Cj0KCQjw1qL6BRCmARIsAD V9Jtal_IEoFnx73QsfkLr2mDZm6DLK4SY83Ms1 Vimg2plOwGBTZKbtRD8aAi52EALw_wcB

33. de Wit E, van Doremalen N, Falzarano D, Munster VJ. SARS and MERS: recent insights into emerging coronaviruses. Nat Rev Microbiol. 2016;14(8):523-534. doi: 10.1038/nrmicro.2016.81

34. Iwanaszko M, Kimmel M. NF-KB and IRF pathways: Cross-regulation on target genes promoter level. $B M C$ Genomics. 2015;16(1):1-8. doi: 10.1186/s12864-0151511-7

35. Lazear HM, Schoggins JW, Diamond MS. Shared and Distinct Functions of Type I and Type III Interferons. Immunity. 2019;50(4):907-923. doi: 10.1016/j. immuni.2019.03.025

36. Vardhana SA, Wolchok JD. The many faces of the anti-COVID immune response. J Exp Med. 2020;217(6):e20200678. doi: 10.1084/jem.20200678

37. Di Mauro G, Scavone C, Rafaniello C, Rossi F, Capuano A. SARS-Cov-2 infection: Response of human immune system and possible implications for the rapid test and treatment. Int Immunopharmacol. 2020;84:106519. doi:10.1016/j.intimp.2020.106519

38. Mescher MF, Curtsinger JM, Agarwal $P$, et al. Signals required for programming effector and memory development by CD8+ T cells. Immunol Rev. 2006;211:81-92. doi: 10.1111/j.01052896.2006.00382.x

39. Prompetchara E, Ketloy C, Palaga T. Immune responses in COVID-19 and potential vaccines: Lessons learned from SARS and MERS epidemic. Asian Pacific J Allergy Immunol. 2020;38(1):1-9. doi: 10.12932/AP-2002200772

40. Qin C, Zhou L, Hu Z, et al. Dysregulation of Immune Response in Patients With Coronavirus 2019 (COVID-19) in Wuhan, China. Clin Infect Dis. 2020;71(15):762-768. doi:10.1093/cid/ciaa248

41. Wang F, Hou H, Luo $\mathrm{Y}$, et al. The laboratory tests and host immunity of COVID-19 patients with different severity of illness. JCl insight. 2020;5(10) :e137799. doi: 10.1172/jci.insight.137799

42. Ganji A, Farahani I, Khansarinejad B, Ghazavi A, Mosayebi G. Increased Expression of CD8 Marker on T-Cells in COVID-19 Patients. Blood Cells, Molecules, and Diseases. 2020;83:102437. doi: 10.1016/j. bcmd.2020.102437

43. Zhao J, Yuan Q, Wang $\mathrm{H}$, et al. Antibody responses to SARS-CoV-2 in patients of novel coronavirus disease 
2019. Clin Infect Dis. 2020;71(16);2027-2034. doi: 10.1093/cid/ciaa344

44. Van Elslande J, Decru B, Jonckheere S, et al. Antibody response against SARS-CoV-2 spike protein and nucleoprotein evaluated by 4 automated immunoassays and 3 ELISAs. Clin Microbiol Infect. 2020:26(11)1557.e1-1557.e7. doi: 10.1016/j. cmi.2020.07.038

45. Long $\mathrm{QX}$, Liu BZ, Deng $\mathrm{HJ}$, et al. Antibody responses to SARS-CoV-2 in patients with COVID-19. Nat Med. 2020;26(6):845-848. doi: 10.1038/s41591-020-0897-1

46. Lou B, Li T-D, Zheng S-F, et al. Serology characteristics of SARS-CoV-2 infection since exposure and post symptom onset. Eur Respir J. 2020;56(2):2000763. . doi:10.1183/13993003.00763-2020

47. To KKW, Tsang OT, Leung WS, et al. Temporal profiles of viral load in posterior oropharyngeal saliva samples and serum antibody responses during infection by SARS-CoV-2: an observational cohort study. Lancet Infect Dis. 2020;20(5):565-574. doi: 10.1016/S14733099(20)30196-1

48. Burbelo PD, Riedo FX, Morishima C, et al. Detection of Nucleocapsid Antibody to SARSCoV-2 is More Sensitive than Antibody to Spike Protein in COVID-19 Patients. Preprint. medRxiv. 2020;2020.04.20.20071423. Published 2020 Apr 24. doi:10.1101/2020.04.20.20071423

49. Siracusano G, Pastori C, Lopalco L. Humoral Immune Responses in COVID-19 Patients: A Window on the State of the Art. Front Immunol. 2020;11:1049. doi: 10.3389/fimmu.2020.01049

50. Li Z, Yi Y, Luo X, et al. Development and Clinical Application of A Rapid IgM-IgG Combined Antibody Test for SARS-CoV-2 Infection Diagnosis. J Med Virol. 2020:92;(9); 1518-1524. doi: 10.1002/jmv.25727

51. Ni L, Ye F, Cheng ML, et al. Detection of SARS-CoV-2Specific Humoral and Cellular Immunity in COVID-19 Convalescent Individuals. Immunity. 2020;52(6):971977.e3. doi: 10.1016/j.immuni.2020.04.023

52. Long Q-X, Tang XJ, Shi QL, et al. Clinical and immunological assessment of asymptomatic SARSCoV-2 infections. Nat Med. 2020;26(8):1200-1204. doi: 10.1038/s41591-020-0965-6

53. Grifoni A, Weiskopf D, Ramirez SI, Smith DM, Crotty $\mathrm{S}$, Sette A. Targets of T Cell Responses to SARS-CoV-2 Coronavirus in Humans with COVID-19 Disease and Unexposed Individuals. Cell. 2020;181:1489-1501.e15. doi: 10.1016/j.cell.2020.05.015

54. Wang $X$, Guo $X$, Xin Q, et al. Neutralizing Antibodies Responses to SARS-CoV-2 in COVID-19 Inpatients and Convalescent Patients. Clin Infect Dis. 2020. doi: 10.1093/CID/CIAA721

55. Okba NMA, Muller MA, Li W, et al. Severe Acute Respiratory Syndrome Coronavirus 2-Specific Antibody Responses in Coronavirus Disease Patients. Emerg Infect Dis. 2020;26(7):1478-1488. doi: 10.3201/ eid2607.200841

56. Xun J, Lu L, Jiang S, Lu H, Wen Y, Huang J. Neutralizing antibody responses to SARS-CoV-2 in a COVID-19 recovered Patient Cohort and Their Implications. medRxiv. 2020.

57. Liu A, Wang W, Zhao X, et al. Disappearance of antibodies to SARS-CoV-2 in a -COVID-19 patient after recovery. Clin Microbiol Infect. 2020. doi: 10.1016/j. cmi.2020.07.009

58. Gudbjartsson DF, Norddahl GL, Melsted P, et al. Humoral Immune Response to SARS-CoV-2 in Iceland. N EnglJ Med. 2020:383;1724-1734. NEJMoa2026116. doi: 10.1056/NEJMoa2026116

59. Cao WC, Liu W, Zhang PH, Zhang F, Richardus JH. Disappearance of antibodies to SARS-associated coronavirus after recovery. $N$ Engl J Med. 2007;357(11):1162-1163. doi: 10.1056/NEJMc070348

60. Payne DC, Iblan I, Rha B, et al. Persistence of antibodies against middle east respiratory syndrome coronavirus. Emerg Infect Dis. 2016;22(10):1824-1826. doi:10.3201/eid2210.160706

61. Wang $\mathrm{K}$, Long $\mathrm{Q}-\mathrm{X}$, Deng $\mathrm{H}-\mathrm{J}$, et al. Longitudinal dynamics of the neutralizing antibody response to SARS-CoV-2 infection. Clin Infect Dis. 2020. doi:10.1093/cid/ciaa1143

62. Wu F, Liu M, Wang A, et al. Evaluating the Association of Clinical Characteristics With Neutralizing Antibody Levels in Patients Who Have Recovered From Mild COVID-19 in Shanghai, China. JAMA Intern Med. 2020;180(10):1356-1362. doi: 10.1001/ jamainternmed.2020.4616

63. Wan S, Yi Q, Fan S, et al. Characteristics of lymphocyte subsets and cytokines in peripheral blood of 123 hospitalized patients with 2019 novel coronavirus pneumonia (NCP). medRxiv. 2020:2020.02.10.20021832. doi: $10.1101 / 2020.02 .10 .20021832$

64. Hu Y, Liang W, Liu L, Li L. Clinical Characteristics of Coronavirus Disease 2019 in China. N Engl J Med. 2020;382:1708-1720. doi: 10.1056/NEJMoa2002032

65. Cann A. Principles of Molecular Virology. $4^{\text {th }}$ ed. Elsevier. 2005.

66. WHO. WHO | DNA vaccines. WHO. 2011. Accessed June 20, 2020. https://www.who.int/biologicals/areas/ vaccines/dna/en/

67. J Carter VS. Virology : Principles and Applications. John Wiley \& Sons Ltd. 2007.

68. Howley DKP. Fields Virology. $6^{\text {th }}$ ed. Lippincot Williams \& Wilkins. 2013.

69. Schlake T, Thess A, Fotin-Mleczek M, Kallen KJ. Developing mRNA-vaccine technologies. RNA Biol. 2012;9(11):1319-1330. doi: 10.4161/rna.22269

70. Jackson LA, Anderson EJ, Rouphael NG, et al. An mRNA Vaccine against SARS-CoV-2 - Preliminary Report. N Engl J Med. 2020;383;1920-1931. doi: 10.1056/ nejmoa2022483

71. EK Wagner, MJ Hewlett, DC Bloom DC. Basic Virology. $3^{\text {rd }}$ ed. Blackwell. 2008.

72. Enjuanes L, Zuniga S, Castano-Rodriguez C, GutierrezAlvarez J, Canton J, Sola I. Molecular Basis of Coronavirus Virulence and Vaccine Development. Adv Virus Res. 2016;96:245-286. doi:10.1016/ bs.aivir.2016.08.003

73. Oxford. Oxford COVID-19 vaccine begins human trial stage | University of Oxford. Published 2020. Accessed June 6, 2020. http://www.ox.ac.uk/news/2020-04-23oxford-covid-19-vaccine-begins-human-trial-stage

74. Folegatti PM, Ewer KJ, Aley PK, et al. Safety and 
immunogenicity of the ChAdOx $1 \mathrm{nCoV}-19$ vaccine against SARS-CoV-2: a preliminary report of a phase $1 / 2$, single-blind, randomised controlled trial. Lancet. Published online 2020;396(10249):467-478. doi: 10.1016/S0140-6736(20)31604-4

75. Zhu F-C, Li Y-H, Guan X-H, et al. Safety, tolerability, and immunogenicity of a recombinant adenovirus type- 5 vectored COVID-19 vaccine: a dose-escalation, open-label, non-randomised, first-in-human trial. The Lancet. 2020;395(10240):P1845-1854. doi: 10.1016/ S0140-6736(20)31208-3
76. Fidel PL, Noverr MC. Could an Unrelated Live Attenuated Vaccine Serve as a Preventive Measure To Dampen Septic Inflammation Associated with COVID-19 Infection?. American Society for Microbiology. 2020;11(3):e00907-20. doi: 10.1128/ mBio.00907-20

77. Carter J S V. Virology : Principles and Applications. John Wiley \& Sons Ltd. 2007.

78. Wang X-YY, Wang B, Wen Y-MM. From therapeutic antibodies to immune complex vaccines. npj Vaccines. 2019;4(2):1-8. doi: 10.1038/s41541-018-0095-z 